\title{
ACTH-dependent Cushing syndrome
}

INSERM

\section{Source}

INSERM. (1999). Orphanet: an online rare disease and orphan drug data base. ACTHdependent Cushing syndrome. ORPHA:99892

Adrenocorticotropic hormone dependent Cushing syndrome (ACTH-dependent CS) is a form of endogenous CS (see this term) caused by abnormal production of ACTH due, in $80 \%$ of cases, to ACTH oversecretion by a pituitary adenoma (Cushing disease, CD) and in $20 \%$ of cases to ectopic ACTH secretion (CS due to EAS; see these terms) by an extrapituitary tumor (in 50\% of cases originating in the lungs or less commonly in the thymus, pancreas, adrenal gland or thyroid) or very rarely due to a tumor secreting both ACTH and corticotrophin-releasing hormone (CRH). 